\title{
What a difference a day makes: inequality and the tax and benefit system from a long-run perspective
}

\author{
Barra Roantree $^{1}$ (D) . Jonathan Shaw ${ }^{2}$
}

Received: 22 October 2015 / Accepted: 3 November 2017 / Published online: 29 December 2017

(C) The Author(s) 2017. This article is an open access publication

\begin{abstract}
Most analyses of inequality and tax and benefit reforms are based on measures of individuals' circumstances at a point in time. But strong age-profiles in earnings, among other characteristics that the tax and benefit system conditions upon, combined with individuals' ability to transfer resources across time suggests that measuring circumstances over longer horizons may lead to a very different picture. In this article, we consider how our impression of inequality and the tax and benefit system changes when the horizon under consideration is extended. We show that inequality is lower, redistribution less extensive, and benefit receipt far more widespread from a longer-run perspective. The choice of accounting period can also lead to a very different assessment of the distributional impact of policy reforms. Our results show the importance of policymakers explicitly considering what it is they are trying to achieve through redistribution: the alleviation of short-run hardship or the reduction of lifetime inequality. While there may be good reasons to pursue both objectives, the group of people affected and the appropriate policy response will differ depending on which is prioritized.
\end{abstract}

Keywords Inequality $\cdot$ Measuring living standards $\cdot$ Redistribution

Barra Roantree

barra.roantree@ifs.org.uk

1 Institute for Fiscal Studies and University College London, London, UK

2 Alan Turing Institute and the Institute for Fiscal Studies, London, UK 


\section{Introduction}

Most analyses of inequality and tax and benefit reforms are based on measures of individuals' circumstances at a point in time, often a week or a month. ${ }^{1}$ However, there are good reasons why we might want to look at horizons longer than a snapshot. First, differences across individuals at a point in time may provide a poor indication of longer-run circumstances. Taxes and benefits depend on a number of key characteristics, such as employment, earnings, health and family composition. These characteristics exhibit considerable shortrun variability and also have marked age profiles (Roantree and Shaw 2014). As a result, differences in earnings, for example, could simply reflect temporary shocks or the fact individuals are at different stages of life. Second, individuals typically have the ability to transfer resources across periods of life (by saving and borrowing) and have some influence over future circumstances through decisions they make today (e.g. partnering and childbearing). Consequently, snapshot measures of income may not give an accurate impression of living standards even in the short-run. Taken together, these observations suggest that income and circumstances measured over longer horizons (such as several years) may lead to very different assessments from those based on short-run or snapshot measures.

In this article, we consider how one's impression of inequality and what the tax and benefit system achieves changes by taking a long-run rather than snapshot perspective. We make three main contributions. First, using the British Household Panel Survey (BHPS), we show that a far greater share of individuals draw on the benefit system over the medium-tolong run than at a snapshot in time. While the proportion of individuals in a family receiving at least one of the main working-age means-tested benefits in the UK is around a fifth at a snapshot on average, this rises to more than half over the full (18-year) horizon our data cover. The reason for this is that many more individuals experience circumstances of interest to policymakers (e.g. unemployment, lone parenthood or disability) at some time during their life than at a point in time. This matters for policy debates that often make a sharp distinction between working and non-working families and imply that the former group is more 'deserving' of support. ${ }^{2}$

Second, we show that the choice of accounting period can be important for assessing the distributional impact of policy reforms. Our results suggest that policies targeted at those considered poorest on a snapshot basis are unlikely to be an effective way of targeting the long-run poor. This means that policymakers should be more specific about what the objectives of a given policy are: the alleviation of short-run hardship or the reduction of lifetime inequality. While there may be good reasons to pursue both, the group of people affected and the appropriate policy response will differ depending on which objective is prioritized. Whereas previous work that considered the distributional impact of reforms over longer periods has tended to focus on indirect tax reforms, ${ }^{3}$ we examine the direct tax and in-work transfer reforms that have dominated the policy agenda in recent decades. Policymakers contemplating such reforms face an important equity-efficiency trade-off in

\footnotetext{
${ }^{1}$ See, for example, Department for Work and Pensions (2013) and Belfield et al. (2014). Some analyses particularly those based on EU Survey of Living Conditions data - use the calendar year prior to interview as the accounting period for income (Iacovou et al. 2012).

${ }^{2}$ See, for example, http://www.telegraph.co.uk/news/politics/david-cameron/11534665/David-Cameron-30hours-of-free-childcare-a-week-for-working-parents.html, http://www.bbc.co.uk/news/election-2015-32603762, and http://www.theguardian.com/politics/2013/apr/07/working-families-exasperated-benefits-harman.

${ }^{3}$ See, for example, Poterba (1989) on excise taxes, Lyon and Schwab (1995) on sin taxes and Caspersen and Metcalf (1994) on VAT.
} 
balancing distributional goals with concerns about the effects the tax and benefit system can have on incentives to work. Understanding the long-run distributional consequences of these reforms is an important part of this trade-off, and something on which there is limited evidence to date.

Third, we provide new evidence on how a longer accounting period changes our perception of inequality and the role of the tax and benefit system. The shortcomings of inequality measures based on annual or snapshot income have long been recognized, with some arguing that differences in age and time preferences could constitute a significant share of inequality as typically measured (e.g. Weizsäcker (1978)). Starting from this observation, many studies have sought to compare the impressions of inequality obtained using annual or snapshot measures to those from simulated measures of lifetime income. Among the first was Blomquist (1981), who used panel data to estimate a series of dynamic income functions and simulate lifetime income for a birth cohort of Swedish males. He found that the distribution of this simulated lifetime income was considerably less unequal than that of annual income. More recently, Brewer et al. (2012), using simulations from a dynamic life-cycle model of women's education, labor supply and savings decisions, found the Gini coefficient for lifetime gross income is about a third lower than annual gross income. Van de Ven (2006) used a similar approach to show that the tax and benefit systems in both the UK and Australia tend to reduce across-household inequality more than within-household inequality during working life.

While simulating lifetime incomes has enabled researchers to assess inequality and redistribution over a longer accounting period, results obtained through this approach are sensitive to the precise specification of the model, as well as on the way in which mobility and heterogeneity are incorporated. ${ }^{4}$ Moreover, as Creedy (1991) noted in an early review of the literature, the scarcity of longitudinal data in most countries exacerbates these already difficult conceptual and technical problems, with the usefulness of a simulation approach limited by the length and quality of data used to estimate the model.

The increasing availability of administrative datasets spanning prolonged periods of time has provided the opportunity to overcome some of these issues. Using Swedish administrative records over the period 1951-1989, Björklund (1993) found that the dispersion of taxable income over working life is around a third to two-fifths lower for men than when measured on an annual basis. Similarly, Kopczuk et al. (2010) show using US social security records that extending the accounting period reduces inequality and increases mobility, but that the large rise in annual earnings inequality has also been reflected in lifetime income. However, these administrative data do not capture benefit and non-employment income, so are limited in what they can tell us about inequality in disposable income or the role of the tax and benefit system, the focus of interest in this paper.

To address these questions, we therefore use longitudinal household survey data; namely the BHPS which collected information about a wide range of socio-economic indicators from around 5,500 households in the UK between 1991 and 2008. Jenkins (2000) used the early waves of these data, and found that averaging income over a six-year period reduced the Gini coefficient by around 10 percent relative to the contemporaneous annual measure. We extend this analysis to cover an 18-year horizon, close to half a working life, and find that commonly-used measures of inequality and redistribution look considerably different

\footnotetext{
${ }^{4}$ For example, De Nardi et al. (2016) show that a life cycle model of consumption incorporating an earnings process that accounts for the rich dynamics observed in administrative data leads to very different predictions about lifetime inequality than if it incorporates the AR(1) process typically used in the literature.
} 
from a long run perspective compared with a snapshot. The Gini coefficients for gross and net income both fall by around a fifth when we use the full (18-year) horizon our data allows compared to a single snapshot. Extending the horizon also leads to a substantial reduction in the effect taxes and benefits have on inequality. This reflects the fact that part of what the tax and benefit system does is to redistribute resources across periods of life, rather than across individuals.

Our findings also relate to the literature that has compared income- to consumption-based measures of inequality and living standards, which are theoretically more closely aligned with lifetime utility relevant for welfare (Poterba 1989; Cutler and Katz 1992). For example, Brewer et al. (2006) find that the increase in consumption inequality is much smaller than the well documented increase in income inequality in the UK over the 1980s. Similarly, using data from the Consumer Expenditure Survey, Krueger and Perri (2006) show that the spike in income inequality in the US over the period 1975-2000 is not matched by consumption inequality, which has increased moderately.

The remainder of the paper is structured as follows. In Section 2 we describe our data. In Section 3 we consider the reach of the benefit system over longer horizons, while in Section 4 we study inequality and redistribution from snapshot and long-run perspectives. Section 5 presents a long-run distributional analysis of selected policy reforms. Finally, Section 6 concludes.

\section{Data}

Our analysis is based on the British Household Panel Survey (BHPS), a panel survey following around 5,500 households in the UK between 1991 and 2008. The BHPS collected information about a wide range of socio-economic indicators, including family composition, employment, income and disability. We use information from all 18 waves and, unless otherwise noted, include all individuals aged 16 or over who are not dependent children. Students and retirees are included but are likely to be under-represented because institutional addresses (e.g. halls of residence and nursing homes) are not sampled. Students tend to be counted at their term-time address, so if they are living away from the parental home they will typically be treated as part of a separate household. To account for nonrandom attrition, all analysis is weighted using the weights provided with the BHPS (see Taylor et al. (2010)). Cross-sectional results are weighted using the cross-sectional enumerated weight, while results that involve extending the horizon across multiple waves use the cross-sectional enumerated weight for wave 1 and the longitudinal enumerated weight thereafter.

With the exception of Section 5, we use the net household income variables derived by Bardasi et al. (2012), described in detail by Jenkins (2011). These are constructed in a way that matches the methodology used for the official inequality and poverty statistics in the (UK Department for Work and Pensions (2013)). Gross annual household income is the sum across all household members of earnings from employment and self-employment, investment and savings income, private and occupational pensions, other market income and private transfers (e.g. maintenance). Net annual household income adds to this the sum across all household members of benefits less taxes. The following benefits are included: income support, jobseeker's allowance, housing benefit, council tax benefit, child benefit, family credit, tax credits (working families' tax credit, working tax credit and child tax credit), maternity grant, state pensions and disability benefits (including incapacity benefit, severe disablement allowance, disability living allowance, attendance allowance, invalid 
care allowance and carer's allowance). The included taxes are income tax and employee National Insurance (but not the community charge or council tax). ${ }^{5}$

In Section 5, we use net income measures that are calculated using TAXBEN - the Institute for Fiscal Studies' tax and benefit microsimulation model for the UK, used previously by Mirrlees et al. (2011) and Blundell et al. (1998) - to assess the distributional impact of various hypothetical policy reforms. We take information from the BHPS on family characteristics and usual gross earnings (from primary jobs only) to calculate tax liabilities and benefit entitlements under different base and reform systems. We ignore unearned income (with the exception of that from private pensions) and assume that all individuals of state pension age have full-entitlement to the basic state pension. The benefits we include are income support, jobseeker's allowance, housing benefit, council tax benefit, child benefit, family credit, tax credits (working families' tax credit, working tax credit and child tax credit), state pension, maternity grant and free school meals; entitlements that we assume are fully taken up by those eligible. The taxes included are income tax, employee National Insurance and council tax.

For both self-reported and simulated income measures, we equivalise using the modified OECD equivalence scale. Income measures across multiple years are calculated as a discounted sum, discounting to the initial period using a discount rate of $2 \%$ (i.e. a discount factor $\beta=1 / 1.02$ ) and expressing incomes in terms of the annual equivalent (i.e. divided by the sum of the discount factors). We discount incomes, rather than simply averaging across periods because income is more valuable to individuals the earlier it is received (e.g. because interest can be earned on it). In practice, our substantive conclusions are unaffected if we do not discount.

\section{The reach of the benefit system}

Individuals experience substantial variation across life in circumstances such as employment, earnings, family composition and disability. Given the tax and benefit system is assessed on the basis of contemporaneous circumstances, considerably more individuals may be entitled to a given benefit at some point over their lives than at a given point in time.

Table 1 demonstrates how a long-run perspective changes our impression of the reach of the benefit system. It shows how the proportion of individuals in a family receiving one of the main British means-tested benefits compares at a point in time on average across the 18 waves of the BHPS (column 1) to ever over all 18 waves (column 2). This allows us to examine the extent to which these benefit claims are concentrated among relatively few, or distributed across many families over both horizons.

For example, although at a point in time on average only $6.8 \%$ of individuals report being in receipt of tax credits (the UK's main means-tested benefit for low income working adults and families with children), this rises to more than a quarter at some point over the full (18-wave) horizon of the BHPS. While extending the accounting period also increases the proportion reporting receipt of income support (payable to very low income adults), housing benefit (payable to low incomes families who rent their homes) and council tax benefit (payable to low income families that are liable to pay council tax on a property in which they

\footnotetext{
${ }^{5}$ For a detailed description of these benefits and taxes, see Hood and Norris Keiller (2016) and Pope and Waters (2016) respectively.
} 
Table 1 Short-run versus long-run receipt of UK's main means-tested benefits

Average across waves

Ever over 18 waves

\begin{tabular}{lcc}
\hline Tax credits $^{\mathrm{a}}$ & $6.8 \%$ & $26.4 \%$ \\
Income support $^{\mathrm{b}}$ & $5.8 \%$ & $17.5 \%$ \\
Unemployment support $^{\mathrm{c}}$ & $1.6 \%$ & $16.4 \%$ \\
Council tax benefit & $10.4 \%$ & $32.6 \%$ \\
Housing benefit & $6.6 \%$ & $17.2 \%$ \\
Any of above benefits & $20.5 \%$ & $54.4 \%$ \\
\hline
\end{tabular}

Source:Authors' calculations using BHPS and TAXBEN.

Note:Includes all non-dependants aged $16+$. Column (1) includes all waves and is weighted using crosssectional weights. Column (2) is calculated for individuals observed in all waves from wave 1 to the destination wave and weighted using longitudinal weights.

a Includes Family Credit - the precursor to tax credits - prior to 1999. The increase in reported receipt as the horizon is extended in part reflects the introduction of this (more generous) system of support from 1999.

${ }^{b}$ Excludes Income Support for the unemployed.

${ }^{\mathrm{c}}$ This measure combines unemployment benefit and Income Support for the unemployed (in operation until October 1996) with jobseeker's allowance (subsequently).

are resident), most striking is the large increase in the proportion of individuals reporting receipt of support for unemployment. This rises from less than $2 \%$ on average across all waves to more than $16 \%$ over the full horizon we examine. Taking all these means-tested benefits together, the share of individuals in families reporting receipt of at least one rises from $20.5 \%$ in a single wave to more than $50 \%$ across all 18 waves.

However, these estimates are likely an underestimate of the true proportion of individuals reached by the means-tested benefit system for two reasons. First, as with any survey-based data, there is under-reporting of benefit claims in the BHPS. ${ }^{6}$ Second, our long-run estimates are based on 18 snapshots of data, and so will miss short benefit claims occurring between waves.

\section{Inequality and Redistribution}

We first look at how two commonly-used measures of inequality evolve as the horizon under consideration is extended: the Gini coefficient and the 90/10 ratio. The Gini coefficient summarizes the disparity between individuals as a number between 0 and 1 . Higher values indicate greater inequality; a value of 0 means no inequality (everyone in the population has the same income), while a value of 1 means perfect inequality (all income is in the hands of a single individual). The $90 / 10$ ratio is an alternative inequality measure, calculated simply as the ratio of the $90^{\text {th }}$ percentile to the $10^{\text {th }}$ percentile of the income distribution. ${ }^{7}$ The lowest possible value is 1 (when the $10^{\text {th }}$ and $90^{\text {th }}$ percentiles are the same) and higher values imply greater inequality.

\footnotetext{
${ }^{6}$ For example, Roantree and Shaw (2014) show that in some waves the BHPS captures less than half the number of families that the Department for Work and Pensions (DWP) reports claim income support, council tax benefit and housing benefit.

${ }^{7}$ The $10^{\text {th }}$ percentile is the income of the individual who is richer than $10 \%$ of the population and poorer than the other $90 \%$. The $90^{\text {th }}$ percentile is defined analogously.
} 


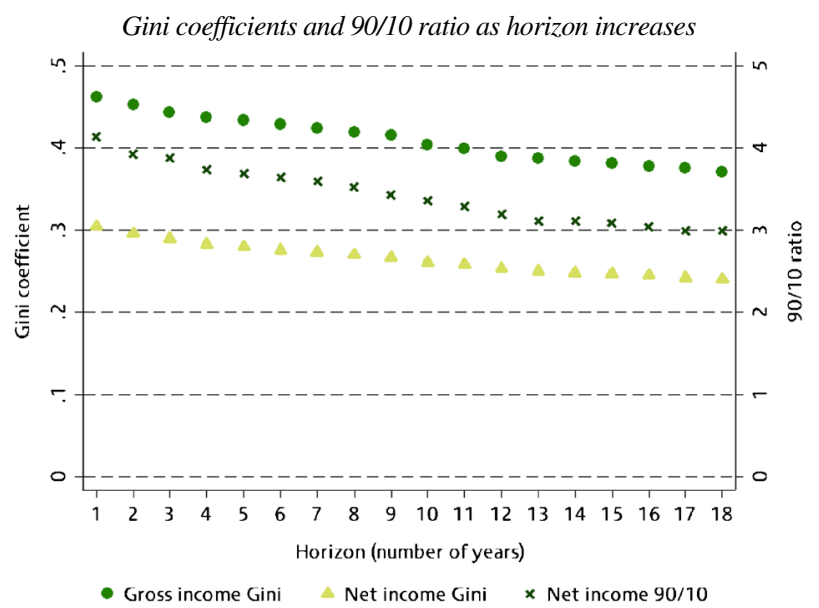

Fig. 1 Gini coefficients and 90/10 ratio as horizon increases. Note: Authors' calculations based on BHPS data. Includes all individuals aged 16 or over who are not dependent children and who have been observed from wave 1 up to the relevant horizon. Income for different horizons is derived from reported income over time and is expressed in real terms, equivalised and discounted. Results are weighted using longitudinal weights (cross-sectional weights for one-year horizon)

Figure 1 shows what happens to the Gini coefficient for gross and net income and the 90/10 ratio for net income as the horizon is extended from one to 18 years. ${ }^{8}$ The figure includes all individuals aged 16 or over who are not dependent children. For both gross and net income, the Gini coefficient falls steadily as more years are added. For example, the gross and net income Ginis fall respectively from 0.461 and 0.304 for a single year to 0.369 and 0.240 across all 18 waves (both declines of around 20\%). The decline is larger for the 90/10 net income ratio, which falls from 4.14 to 2.97 (a $28 \%$ reduction). ${ }^{9}$

The reason inequality falls as the horizon increases is that some of the variation in income across individuals at a point in time is transitory and will tend to average out when considering multiple years together. ${ }^{10}$ Initially proposed as a measure of income mobility, the Shorrocks (1978) index has been widely used in the literature to assess the extent to which inequality is reduced as the accounting period is extended. The index ranges between 0 (indicating complete immobility of relative incomes) and 1 (indicating complete mobility). Applying this measure to the Gini coefficient for net income, we find that extending the accounting period to 18-years reduces inequality by almost a fifth $(0.172)$. This is larger than the 9\% reduction estimated by Jarvis and Jenkins (1998) over the first four waves of the BHPS, but confirms their (at the time, tentative) conclusion that the inequality reducing effects of lengthening the accounting period appears to converge quite rapidly. The effect is slightly smaller for gross incomes, at $15.7 \%$ over the 18 -year horizon we assess.

\footnotetext{
${ }^{8}$ We do not include the $90 / 10$ ratio for gross income because the $10^{\text {th }}$ percentile of the gross income distribution is often close to zero, making the 90/10 ratio large and very volatile.

${ }^{9}$ We obtain very similar results using the simulated data analyzed in Section 5 of the paper.

${ }^{10}$ In theory, changes to the Gini coefficient as the horizon is extended could reflect changes to the annual income distribution over time. But this is unlikely to play an important role here since the annual Gini coefficient was relatively stable over the period in question, and if anything, may have increased slightly: see Belfield et al. (2014).
} 


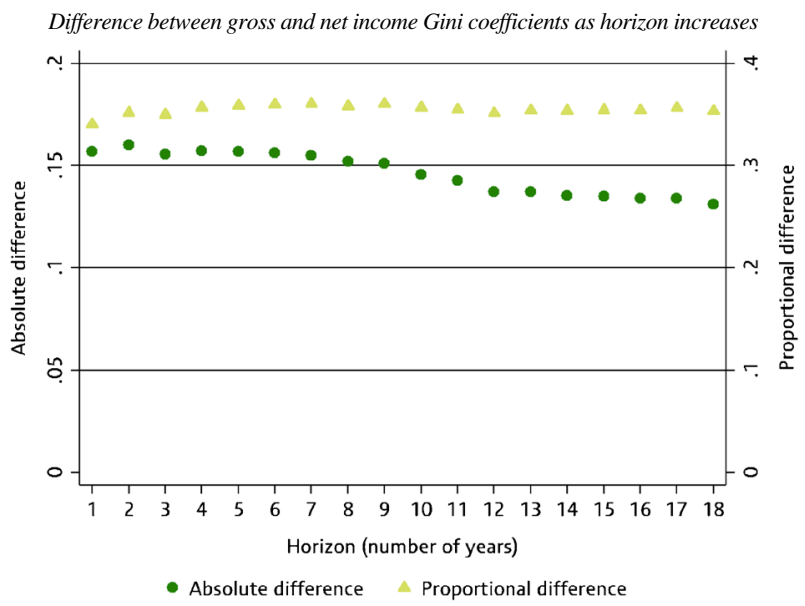

Fig. 2 Difference between gross and net income Gini coefficients as horizon increases. Note: Authors' calculations based on BHPS data. Includes all individuals aged 16 or over who are not dependent children and who have been observed from wave 1 up to the relevant horizon. Income for different horizons is derived from reported income over time and is expressed in real terms, equivalised and discounted. Results are weighted using longitudinal weights (cross-sectional weights for one-year horizon)

As already shown, taking a longer-run perspective changes our assessment of the degree of income inequality in society. A related question is how it changes our assessment of the role the tax and benefit system plays in reducing this inequality. We use two simple measures to assess what difference extending the accounting period makes: the absolute difference between the Gini coefficient for gross and net income (often called the Reynolds-Smolensky index of redistributive effect) and the proportional difference in these Ginis. In both cases, positive values indicate inequality-reducing redistribution, and the converse for negative values.

Figure 2 shows how these two measures evolve as the horizon under consideration is extended. While the proportional difference between the gross and net income Gini remains roughly constant at about 0.35 across all horizons, the Reynolds-Smolensky index falls by almost a fifth over the full 18 -wave horizon from 0.157 to 0.129 , with virtually all of the decline occurring as the horizon is extended from 7 to 12 waves.

What explains this decline in the effectiveness of taxes and benefits at reducing inequality in absolute terms as the horizon increases? In part, it is because when measured over a longer horizon, there is less inequality for redistribution to address. However, it also reflects the fact that, from a life-cycle perspective, part of what the tax and benefit system does is effectively to redistribute resources across periods of life (rather than across individuals), with benefits at one age financed by taxes at another. This means that a growing share of the total amount spent on benefits and raised in taxes is ineffective at reducing long-run inequality across individuals.

To get a sense of what is driving this, we can look at net taxes (taxes less benefits) as a proportion of net income across the income distribution and compare the snapshot and long-run results. ${ }^{11}$ This is shown in Fig. 3. Our snapshot income measure is equivalised

\footnotetext{
${ }^{11}$ In principle, we could look at net taxes as a proportion of gross (rather than net) income. In this case, the snapshot bar for the bottom decile becomes highly negative because almost half of that decile has zero gross income. This distorts the scale, making the rest of the graph unreadable. Nevertheless, the same patterns emerge as for the net income case discussed in the text.
} 


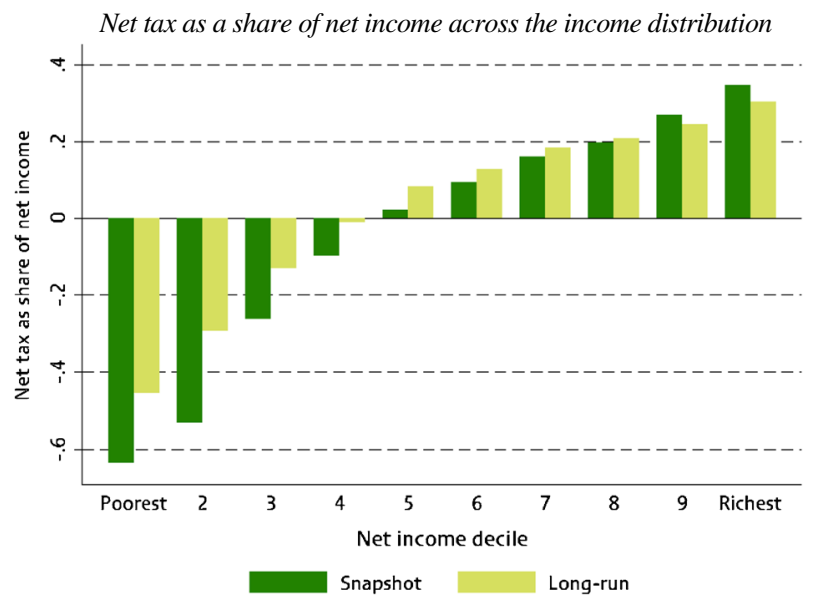

Fig. 3 Net tax as a share of net income across the income distribution. Note: Authors' calculations based on BHPS data. Includes all individuals aged 16 or over who are not dependent children and who are observed in wave 1 ('snapshot' series) or in each of waves 1-18 ('long-run' series). Income is derived from reported income and is expressed in real terms, equivalised and (for the long-run series) discounted. The snapshot series is weighted using cross-sectional weights, while the long-run series is weighted using longitudinal weights. For the snapshot series, both the income deciles and the net tax shares are calculated using snapshot income from wave 1. Likewise, the long-run series is based on long-run income deciles and net tax shares across all 18 waves. Deciles and changes in net income are defined on the basis of equivalised income. Changes in net income are average changes as a percentage of average incomes in each decile

net income in wave 1 of the BHPS. Our long-run income measure is discounted average equivalised net income over all 18 waves of the BHPS.

If the tax and benefit system were equally effective at reducing snapshot and long-run inequality, we would expect the bars to be similar across the two series. In fact, the snapshot pattern is considerably more progressive, with the difference particularly marked at the bottom of the income distribution. This means that the tax and benefit system is more effective at redistributing toward those who are temporarily poor than toward those who are poor in the long run. At least part of this is because gross incomes are less unequally distributed in the long run, meaning the tax and benefit system has less work to do.

We can analyze this issue more formally, decomposing total redistribution into two components: redistribution across periods of life (intrapersonal redistribution) and redistribution across individuals (interpersonal redistribution). ${ }^{12}$

Such an exercise requires a definition of a no-redistribution baseline. Were we able to attribute the benefit of all government spending back to individuals, then the natural baseline would be where taxes equal total benefits (cash benefits and public services) for each individual. But data limitations mean that we cannot easily take public services into account. As a result, the choice of baseline is less clear-cut because the system raises net revenue (to fund public services). We therefore use two revenue-neutral alternatives: baselines where taxes net of benefits are either a constant lump-sum amount or a constant proportion of gross income.

\footnotetext{
${ }^{12}$ For this analysis, redistribution simply refers to transfers of resources between households via taxes and benefits, regardless of whether they reduce inequality.
} 
Let $N \equiv B-T$ be net benefits (benefits less taxes), $K$ be the revenue-neutral noredistribution baseline, and $R=N-K$ be the amount of redistribution relative to the no-redistribution baseline. Notice that there is nothing in this definition that requires redistribution to be from rich to poor: it is simply a transfer of resources. We will use $i$ to index individuals and $t$ to index time, and the absence of a subscript indicates summation, e.g. $R_{i}=\sum_{t} R_{i t}$. Following Hussénius and Selén (1994), total redistribution can then be decomposed into intrapersonal and interpersonal components as:

$$
\begin{aligned}
& \underbrace{\sum_{i} \sum_{t}\left(R_{i t} \mid R_{i t}>0\right)}_{\text {Total redistribution }} \\
& =\underbrace{\sum_{i} \min \left\{\sum_{t}\left(R_{i t} \mid R_{i t}>0\right),-\sum_{t}\left(R_{i t} \mid R_{i t}<0\right)\right\}}_{\text {Intrapersonal redistribution }}+\underbrace{\sum_{i} 1\left[R_{i}>0\right] R_{i}}_{\text {Interpersonal redistribution }}
\end{aligned}
$$

The left-hand side of the equation is total redistribution. The summation only includes periods when redistribution is positive (as indicated by the condition to the right of the vertical bar 'l') to avoid everything canceling out: since we are comparing against a revenueneutral baseline, redistribution toward one individual at a given age must come from another individual or age. If we express the intrapersonal component as a proportion of total redistribution, this gives the share of redistribution that is effectively across periods of life.

Figure 4 shows how intrapersonal redistribution as a share of total redistribution changes with the accounting period for our alternative no-redistribution baselines (lump sum and

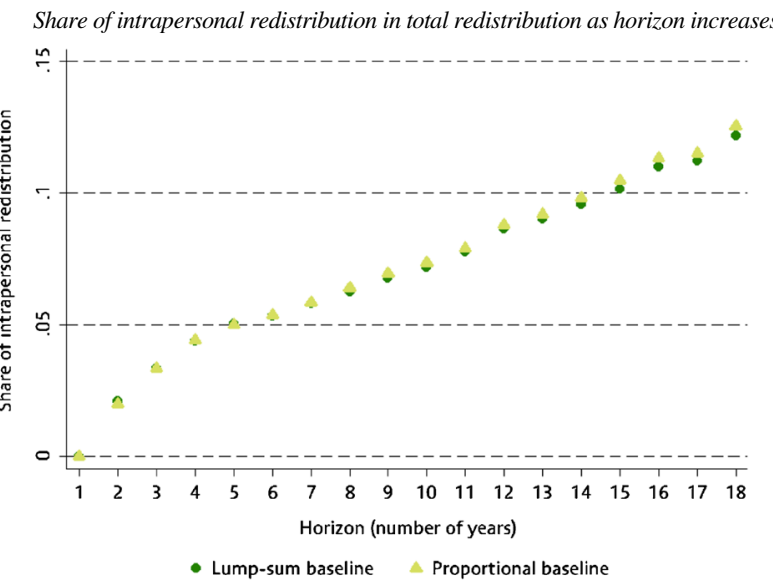

Fig. 4 Share of intrapersonal redistribution in total redistribution as horizon increases. Note: Authors' calculations based on BHPS data. Includes all individuals aged 16 or over who are not dependent children and who have been observed from wave 1 up to the relevant horizon. Income is expressed in real terms and discounted. Results are weighted using longitudinal weights (cross-sectional weights for the one-year horizon). Instead of equivalising incomes, redistribution is assumed to be split equally between members of a couple. This ensures that the decomposition adds up correctly. The series labeled 'lump-sum baseline' defines no redistribution as the situation in which each individual pays the same cash amount in net taxes. The series labeled 'proportional baseline' defines no redistribution as the situation in which each individual pays the same proportion of their gross income in net taxes. In both cases, the level of the baseline is set so as to be revenue-neutral relative to the actual system 
proportional), though there is very little difference between them. By definition, there is no intrapersonal redistribution with only one period. As the number of periods increases, the share of intrapersonal redistribution rises steadily, exceeding $10 \%$ of the total after 15 years: in other words, more than a tenth of redistribution has no effect on inequality over this longer horizon.

While we are constrained by the length of our data, it does not seem unreasonable to expect the share of redistribution that is intrapersonal to continue to rise as the horizon is extended further for two reasons. First, much redistribution across periods of life is likely to happen at a lower frequency than 18 waves of data can capture. The benefit system redistributes substantial amounts of resources toward the elderly and those with children, circumstances that most of the population will experience at some point over their lives. Second, estimates from simulated and administrative data elsewhere suggest the share of lifetime redistribution that is intrapersonal is substantially higher than over the 18-year horizon we observe. For example, using a simulation approach, Falkingham and Harding (1996) estimate that between 62 and $71 \%$ of redistribution in Britain is intrapersonal when assessed over a full lifetime, while Bovenberg et al. (2008) find that this proportion is about threefourths using Danish administrative data. In short, a large part of what the tax and benefit system does is to redistribute resources across periods life, rather than between people.

\section{Assessment of policy reforms}

Policymakers and the public are frequently interested in the distributional impact of actual and hypothesized policy reforms. For example, charts showing gains and losses across the income distribution have become a staple of the policy analysis carried out by the government and others on Budget day in the UK and elsewhere (e.g. HM Treasury (2014)). But such analysis is generally based on cross-sectional data, and so only shows the impact of a reform at a given point in time. As individuals experience significant changes in their circumstances over time, those most affected by a reform at a point in time may be a very different group from those affected most over the long term.

To illustrate this, we line individuals up from poorest to richest based on their net family income at a snapshot in time (accounting for family size) and divide them into 10 equally sized groups, or deciles. We then calculate what proportion of individuals in each snapshot income decile end up in the poorest and richest long-run decile over the full 18-wave span of the BHPS. We then repeat this for each snapshot year and take the average. The result is shown in Fig. 5. While the majority of individuals in the richest snapshot income decile are also in the richest long-run income decile (more than 60\%), only $35 \%$ of those in the poorest snapshot decile end up in the corresponding long-run decile. Almost as many (31\%) end up in the $2^{\text {nd }}$ poorest long-run decile, with the remainder spread mostly across the $3^{\text {rd }}$ to $5^{\text {th }}$ deciles.

One consequence of this is that snapshot and long-run distributional impacts of policy measures may look quite different. In particular, measures designed to redistribute to the snapshot poor may have relatively little effect on the long-run poor. To illustrate the importance that these differences can have, we now contrast the snapshot and long-run distributional effects of three policy reforms which have been considered by policymakers in the UK as ways of redistributing to the less well off: an increase in the income tax-free allowance, a cut in income tax, and an increase in the generosity of transfers to low-income working families. 


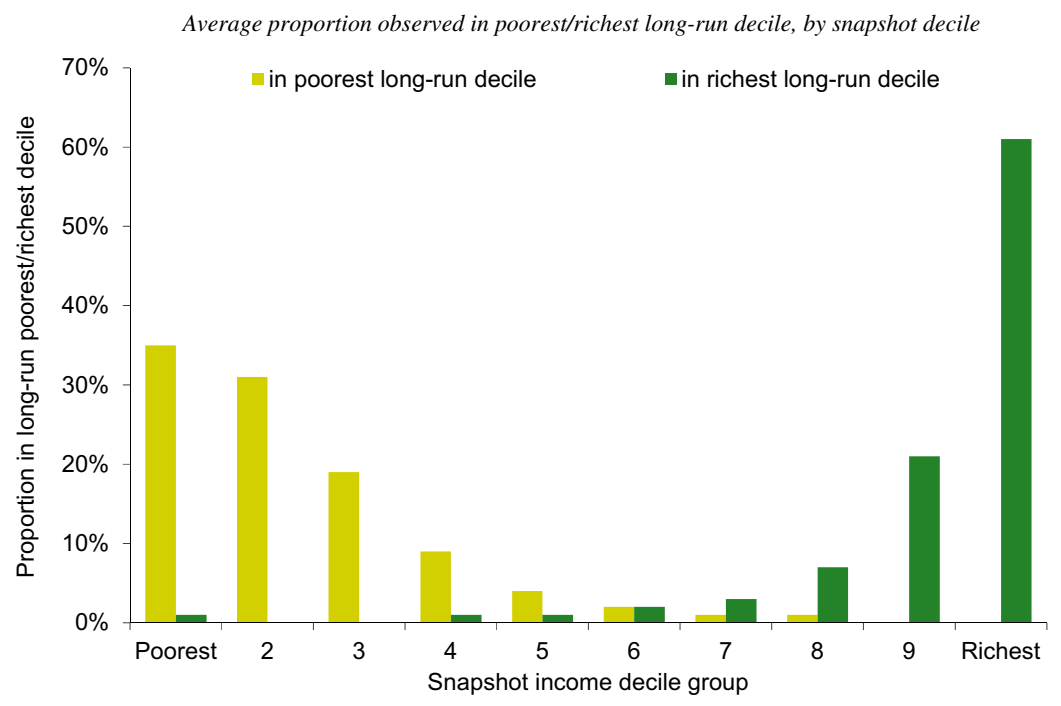

Fig. 5 Average proportion observed in poorest/richest long-run decile, by snapshot decile. Note: Authors' calculations based on BHPS data. Includes all individuals aged 16 or over who are not dependent children

To isolate the distributional impact of a policy change at either a snapshot in time or over a longer horizon, one must specify the (counterfactual) policy environment that would have applied in the absence of the reform. We therefore use TAXBEN - the Institute for Fiscal Studies' tax and benefit microsimulation model - to calculate what households' tax liabilities, benefit entitlements and disposable incomes would have been had the same tax and benefit system (adjusted for prices) been in place continuously throughout the 18 waves covered by the BHPS. Unlike individuals' reported (actual) incomes analyzed above - which are the product of 18 different tax and benefit systems across the period we consider - these simulated data provide a single counterfactual and allow us to calculate the average proportional change in both snapshot and long-run equivalised disposable income that result from the reforms we consider. Doing so provides a clear, coherent, way of assessing the distributional impact of these reforms, as well as being the measure most familiar to policymakers. The analysis we present uses the individual rather than household as the unit of analysis, as changes in family structure over time make household-level analysis problematic. In this sense, the snapshot measure is comparable to official UK statistics on poverty and inequality (Department for Work and Pensions 2013). ${ }^{13}$

\subsection{Increasing the income tax-free allowance}

Between 2010 and 2015, the UK coalition government sought to increase after-tax income for poorer households by raising the personal allowance (which is deducted from total income before tax to give taxable income) to $£ 10,000$ per year. To this end, it made repeated discretionary increases above those required by automatic statutory uprating, the practice whereby personal tax thresholds and benefit entitlements are increased in line with inflation

\footnotetext{
${ }^{13}$ We do not explore the effect of these reforms on the measures of inequality and redistribution discussed earlier as they are insensitive to changes in income of the magnitude implied by even these substantial reforms.
} 
Increase in personal (tax-free) allowance

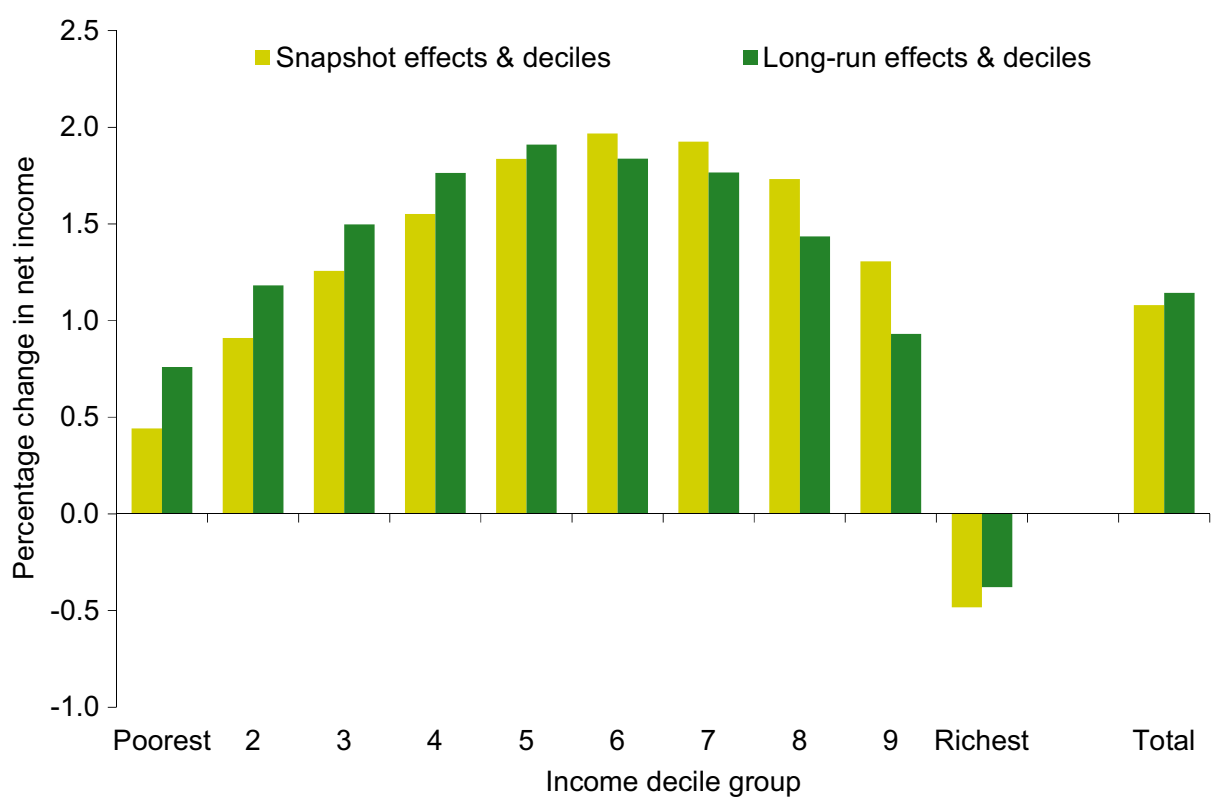

Fig. 6 Increase in personal (tax-free) allowance. Note: Authors' calculations based on BHPS data and net incomes simulated using TAXBEN assuming full take-up. Includes all individuals aged 16 or over who are not dependent children and who are observed in wave 1 ('snapshot effects and deciles' series) or across all 18 waves (the other series)

unless Parliament explicitly decides otherwise. Gains were restricted to basic-rate taxpayers (currently $20 \%$, paid on the first band of taxable income) by making corresponding cuts to the higher-rate threshold, the point at which a $40 \%$ rate of income tax begins to apply. The net cost of these measures was an estimated $£ 10.7$ billion per year in 2015 prices. We contrast the snapshot and long-run distributional impacts of such an increase in the personal allowance against a no-reform counterfactual in which the personal allowance and higher-rate threshold rose in line with statutory indexation.

Figure 6 shows that, on a snapshot basis, the reform primarily benefits individuals in the upper half of the income distribution who tend to be basic-rate income tax payers, with gains peaking at $2 \%$ of disposable income for those in the $6^{\text {th }}$ decile. The poorest decile see an average gain of less than $0.5 \%$, as few of these individuals earn enough in a given year to pay any income tax. By contrast, the richest snapshot decile experiences a loss on average, as those with incomes above $£ 100,000$ do not receive a full personal allowance and so do not benefit from the increase, but pay more in tax because of the offsetting reductions to the higher rate threshold. ${ }^{14}$

Adopting a long-run perspective moderates this distributional pattern somewhat, particularly at either end of the distribution. This is as some individuals in the poorer long-run deciles do earn enough in some periods to pay income tax, and so benefit from the increased personal allowance in these periods. However, gains remain concentrated among individuals

\footnotetext{
${ }^{14}$ Since $2010-11, £ 1$ of the personal allowance has been withdrawn from individuals for every $£ 2$ of taxable income above $£ 100,000$.
} 
1 percentage point reduction in the basic rate of income tax

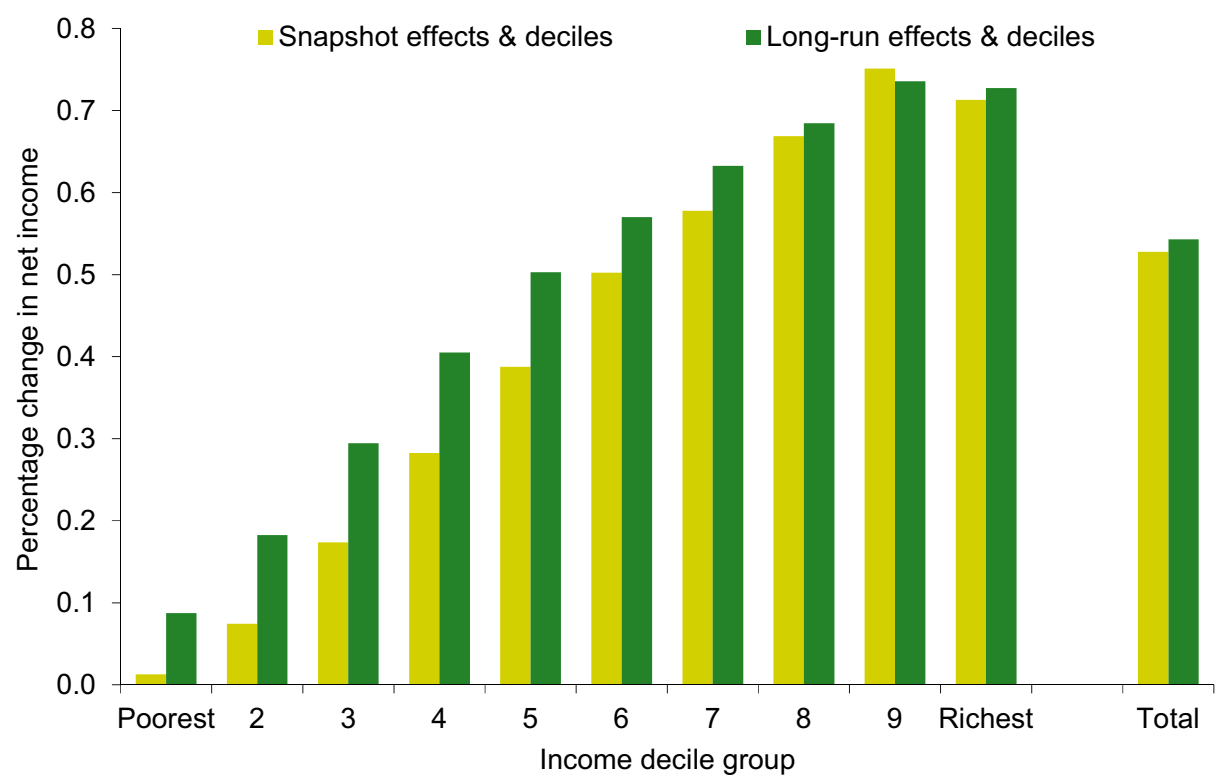

Fig. 71 percentage point reduction in the basic rate of income tax. Note: Authors' calculations based on BHPS data and net incomes simulated using TAXBEN assuming full take-up. Includes all individuals aged 16 or over who are not dependent children and who are observed in wave 1 ('snapshot effects and deciles' series) or across all 18 waves (the other series)

in the upper half of the long-run income distribution, who pay income tax at the basic-rate in many (or all) periods.

Although claimed as progressive by its proponents, ${ }^{15}$ the analysis here shows that increases to the personal allowance primarily benefit those in the upper half of both the snapshot and long-run distribution of income. Such increases represent an expensive and ineffective way of redistributing to those at the bottom of the income distribution, even from a long-run perspective.

\subsection{Reducing the basic-rate of income tax by 1 percentage point}

The second reform we consider involves reducing the basic-rate of income tax by 1 percentage point. This has been a popular policy among British governments of all hues, with the basic-rate falling from $35 \%$ in $1976-77$ to $20 \%$ by $2008-09$, with the largest cuts made during the late 1970 s and early 1980 s.

Figure 7 shows that the reform looks strongly regressive from a snapshot perspective, with gains almost uniformly increasing with income decile group. The poorest individuals are on average essentially unaffected by the rise using a snapshot measure, because they earn too little to pay income tax and so do not gain from a reduction in the basic-rate. The

\footnotetext{
${ }^{15}$ For example, the then Deputy Prime Minister Nick Clegg told members of Parliament in February 2012 that increasing the personal allowance was "an extremely effective way of making the tax system more progressive" (see https://hansard.parliament.uk/Commons/2012-02-07/debates/12020774000026/ TopicalQuestions\#contribution-12020774000119).
} 
In-work tax credits reform

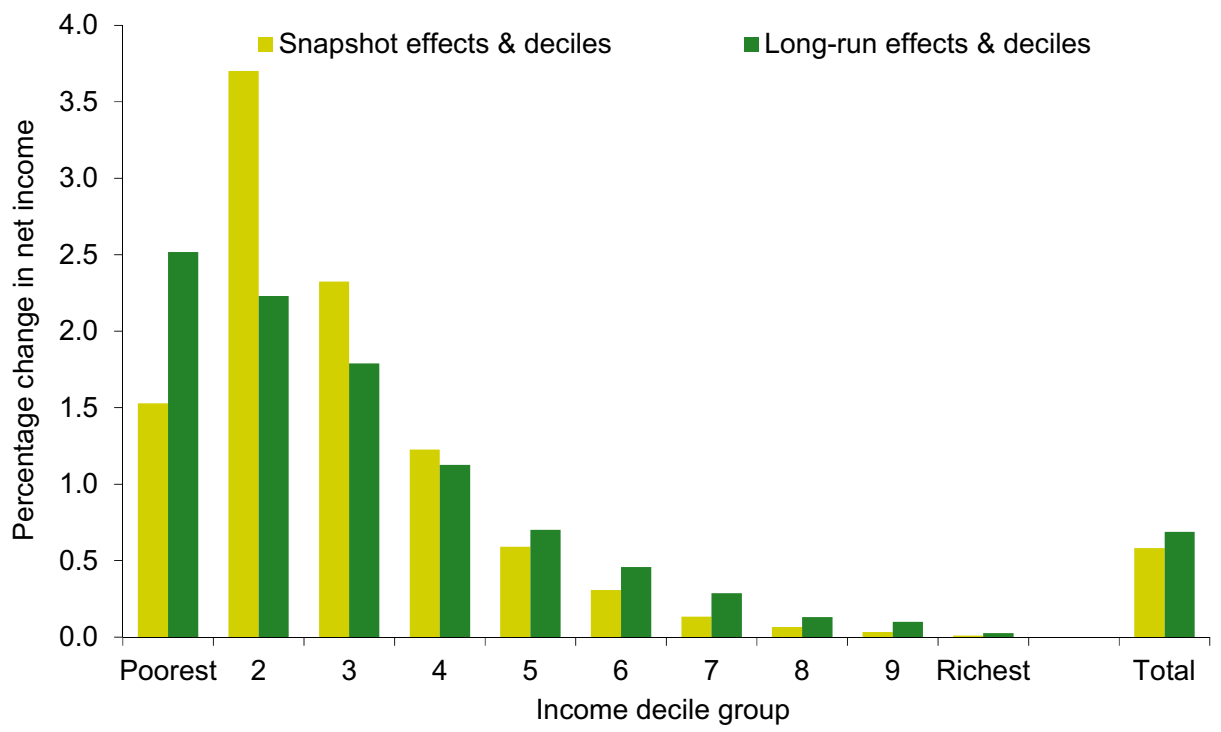

Fig. 8 In-work tax credits reform. Note: Authors' calculations based on BHPS data and net incomes simulated using TAXBEN assuming full take-up. Includes all individuals aged 16 or over who are not dependent children and who are observed in wave 1 ('snapshot effects and deciles' series) or across all 18 waves (the other series)

proportional gains decline slightly in the richest decile as individuals here are mostly higher rate taxpayers who gain by a fixed cash amount.

As with the personal allowance reform, adopting a long-run perspective attenuates the distributional pattern, particularly at the bottom of the distribution. This is because many of the long-run poor are not poor in every period, and so end up benefiting from the income tax cut in some periods. However, gains continue to be concentrated among the long-run rich. This reflects the fact that incomes are more persistent at the top, and that the long-run rich tend to spend the majority of their lives in the upper half of the snapshot income distribution: indeed over half of those in the richest long-run decile are always in the richest snapshot quintile. As a result, policy measures designed to target the long-run rich can be reasonably well proxied by measures targeting those with high incomes at a point in time. However, as we will now see, the same cannot be said of measures designed to target the long-run poor.

\subsection{Increasing the generosity of in-work tax credits}

The final reform we model is the introduction of Working Families Tax Credit (WFTC), a means-tested benefit for working families with children, similar to the Earned Income Tax Credit (EITC) in the US. The reform substantially increased the benefit entitlements of lowincome parents working more than 16 hours per week, particularly those without a partner. 
The explicit motivation of the reform was to redistribute resources to low-paid families while encouraging out-of-work parents to move into employment. ${ }^{16}$

Figure 8 shows that on a snapshot basis, the distributional impact of the reform looks quite progressive, with gains concentrated among the poorest half of individuals. However, the largest average gains are found in the second decile: $3.7 \%$, more than double that in the poorest decile. This is because WFTC was targeted at low-income working parents, rather than the out-of-work families who constitute the bulk of those in the poorest snapshot decile. One might therefore be tempted to conclude that WFTC, while highly redistributive, benefited the quite rather than very poor.

However, the distributional impact of the reform looks more progressive from a long-run perspective, with those in the poorest long-run decile gaining most (by $2.5 \%$ on average) and gains declining monotonically across richer long-run deciles. The reason for this is because the long-run poor spend a large proportion of their lives in low-paid employment, which places them in the $2^{\text {nd }}$ and $3^{\text {rd }}$ poorest snapshot deciles - where gains from the reform are concentrated - rather than in the very poorest decile. This is consistent with the finding of Brewer et al. (2012) that being a low-wage parent - particularly a low-wage lone parent is a good indicator of having low lifetime income.

\section{Conclusion}

In this article, we have considered the difference that taking a longer-run perspective makes to our impression of inequality and the role of the tax and benefit system. We have shown that extending the accounting period from a snapshot to one based on multiple periods can substantially change our impression of the reach of the benefit system, of standard measures of inequality and redistribution, and of the distributional impact of reforms to the tax and benefit system. Our findings build on previous work that has (for the most part) relied on simulated data and tended to focus on indirect taxes when analyzing the long-run distributional impacts of reforms, rather than to direct taxes and in-work benefits that have been the focus of considerable international policy debate over recent years.

We found that benefit receipt is not restricted to just a small subset of people in the long run, but encompasses more than half of all individuals over a period of 18 years. This goes against the frequently expressed notion that it is the same small group people who remain on benefits every year, relying on the rest of the population to support them. We also find that while inequality tends to decline as the horizon is extended, so does the effectiveness of the tax and benefit system at reducing inequality in absolute terms. The decline in inequality over a longer horizon is explained by the transitory nature of some of the variation in income across individuals at a point in time, which will tend to average out when considering multiple years together. The decline in effectiveness results partly from the fact that some of what the tax and benefit system does is effectively to redistribute resources across periods of life rather than across individuals, and partly because there is less inequality for redistribution to address.

The distributional impact of tax and benefit reforms is also sensitive to the choice of accounting period. We show that the distributional impact of the reform to Working Families' Tax Credit looks more progressive from a long-run than from a snapshot perspective,

\footnotetext{
16 See Dilnot and McCrae (1999) and Blundell et al. (2000) for further details of the reform, and how WFTC operated.
} 
particularly for the bottom decile. In contrast, changing the horizon has relatively little effect when considering increases to the personal allowance or reductions in the basic-rate of income tax. This is as the long-run poor rarely earn enough to pay income tax in any period, and so rarely benefit from cuts to the basic rate of income tax, or increases to the personal allowance.

The analysis here shows the importance of policymakers explicitly considering what it is they are trying to achieve through redistribution: the alleviation of short-run hardship or the reduction of lifetime inequality. While there may be good reasons to pursue both objectives, the group of people affected and the appropriate policy response will differ depending on which is prioritized.

Acknowledgments The authors gratefully acknowledge funding from the Nuffield Foundation (OPD/40976), the European Research Council (reference ERC-2010-AdG-269440-WSCWTBDS) and the ESRC Center for the Microeconomic Analysis of Public Policy based at the Institute for Fiscal (RES544-28-5001, ES/M010147/1). The British Household Panel Survey (BHPS) is produced by the ESRC UK Longitudinal Studies Center, together with the Institute for Social and Economic Research at the University of Essex. Data for the BHPS were supplied by the UK Data Service. The BHPS is also crown copyright material and reproduced with the permission of the Controller of HMSO and the Queen's Printer for Scotland. The authors thank Peter Levell for assistance with the BHPS, and Carl Emmerson, Andrew Hood, Paul Johnson and Cormac O'Dea for comments on earlier drafts. All errors remain the responsibility of the authors.

Open Access This article is distributed under the terms of the Creative Commons Attribution 4.0 International License (http://creativecommons.org/licenses/by/4.0/), which permits unrestricted use, distribution, and reproduction in any medium, provided you give appropriate credit to the original author(s) and the source, provide a link to the Creative Commons license, and indicate if changes were made.

\section{References}

Bardasi, E., Jenkins, S.P., Sutherland, H., Levy, H., Zantomio, F.: British Household Panel Survey Derived Current and Annual Net Household Income Variables, Waves 1-18, 1991-2009. 9th Edition. University of Essex. UK Data Service. SN: 3909 (2012)

Belfield, C., Cribb, J., Hood, A., Joyce, R.: Living Standards, Poverty and Inequality in the UK: 2014 IFS Report R96, Institute for Fiscal Studies, London (2014)

Björklund, A.: A comparison between actual distributions of annual and lifetime income: Sweden 1951-89. Rev. Income Wealth 39, 377-386 (1993)

Blomquist, N.S.: A comparison of distributions of annual and lifetime income: Sweden Around 1970. Rev. Income Wealth 27, 243-264 (1981)

Blundell, R., Duncan, A., Meghir, C.: Estimating labor supply responses using tax reforms. Econometrica 66, 827 (1998)

Blundell, R., Duncan, A., McCrae, J., Meghir, C.: The labour market impact of the working families' tax credit. Fisc. Stud. 21, 75-104 (2000)

Bovenberg, A.L., Hansen, M.I., Sørensen, P.B.: Individual savings accounts for social insurance: rationale and alternative designs. Int. Tax Public Financ. 15, 67-86 (2008)

Brewer, M., Goodman, A., Leicester, A.: Household spending in Britain: what can it teach us about poverty? The Policy Press, Bristol (2006)

Brewer, M., Dias, M.C., Shaw, J.: Lifetime inequality and redistribution. Working paper W12/23, Institute for Fiscal Studies, London (2012)

Caspersen, E., Metcalf, G.: Is a value-added tax regressive? Annual versus lifetime incidence measures. Natl. Tax J. 47, 731-746 (1994)

Creedy, J.: Lifetime earnings and inequality. Economic Record 67, 46-58 (1991)

Cutler, D.M., Katz, L.F.: Rising inequality? Changes in the distribution of income and consumption in the 1980's. Am. Econ. Rev. 82, 546-51 (1992) 
Department for Work and Pensions: Households below average income: an analysis of the income distribution 1994/95-2011/12. Department for Work and Pensions, London (2013)

De Nardi, Mariacristina, G.F., Pardo, G.P.: The implications of richer earnings dynamics for consumption and wealth. WP no. 21917. National Bureau of Economic Research (2016)

Dilnot, A., McCrae, J.: The Family Credit System and the Working Families' Tax Credit in the United Kingdom. Briefing Note No. 3, Institute for Fiscal Studies, London (1999)

Falkingham, J., Harding, A.: Poverty alleviation versus social insurance systems: A comparison of lifetime redistribution. North Holland, Amsterdam (1996)

Hood, A., Norris Keiller, A.: A survey of the GB benefit system, IFS Briefing Note BN13, Institute for Fiscal Studies, London (2016)

HM Treasury: Budget 2014, Controller of her majesty's Stationery Office, London (2014)

Iacovou, M., Kaminska, O., Levy, H.: Using EU-SILC data for cross-national analysis: strengths, problems and recommendations. WP 2012-03, ISER, Essex (2012)

Jarvis, S., Jenkins, S.P.: How Much Income Mobility is There in Britain? Econ. J. 108, $428-443$ (1998)

Jenkins, S.P.: Modelling Household Income Dynamics. J. Popul. Econ. 13, 529-567 (2000)

Jenkins, S.P.: Changing fortunes: income mobility and poverty dynamics in britain. Oxford University Press, Oxford (2011)

Kopczuk, W., Saez, E., Song, J.: Earnings inequality and mobility in the United States: evidence from social security data since 1937. Q. J. Econ. 125(1), 91-128 (2010)

Krueger, D., Perri, F.: Does income inequality lead to consumption inequality? Evidence and theory. Rev. Econ. Stud. 73, 163-193 (2006)

Lyon, A., Schwab, R.: Consumption taxes in a life-cycle framework: are sin taxes regressive Rev. Econ. Stat. 3, 389-405 (1995)

Mirrlees, J., Adam, S., Besley, T., Blundell, R., Bond, S., Chote, R., Gammie, M., Johnson, P., Myles, G., Poterba, J. (eds.): Tax by design: the Mirrlees review. Oxford University Press, Oxford (2011)

Pope, T., Waters, T.: A survey of the UK tax system, IFS Briefing Note BN09, Institute for Fiscal Studies, London (2016)

Poterba, J.M.: Lifetime incidence and the distributional burden of excise taxes. Am. Econ. Rev. 79, 325-330 (1989)

Roantree, B., Shaw, J.: The case for taking a life-cycle perspective: inequality, redistribution, and tax and benefit reforms. Report R92, Institute for Fiscal Studies, London (2014)

Shorrocks, A.: Income inequality and income mobility. J. Econ. Theory 19, 376-393 (1978)

Taylor, M.F., Brice, J., Buck, N., Prentice-Lane, E. (eds.): British Household Panel Survey user manual volume a: introduction, technical report and appendices. University of Essex, Colchester (2010)

van de Ven, J.: The distributional effects of taxation in Australia and the United Kingdom: evidence from microsimulations. In: Creedy, J., Kalb, G. (eds.) Dynamics of Inequality and Poverty (Research on Economic Inequality, Volume 13) Emerald Group Publishing Limited, pp. 81-122 (2006)

Weizsäcker, C.C.V.: Annual income, lifetime income and other income concepts in measuring income distribution. In: Kelle, W.H., Shorrocks, A.F. (eds.) Personal Income Distribution, pp. 101-5. North-Holland, Amsterdam (1978) 